\title{
EXAMINING RELIGIOSITY AND SPIRITUALITY CONCEPTS AND THEIR PROTECTIVE ROLE IN HEALTH RISK BEHAVIOUR: TESTING FOR MUTUAL MEDIATION
}

\author{
S Mashegoane \\ University of Limpopo (Corresponding Author) \\ M Makhubela \\ University of Pretoria
}

\begin{abstract}
This study sought to establish the conceptual relationship between intrinsic religiosity and spirituality by evaluating their capacity to mediate one another. Analysis was done using a cross-sectional data provided by university students $(\mathrm{N}=333)$ from the Limpopo Province, South Africa. SEM analysis was used to test two hypothesised mediation models: 1) in which intrinsic religiosity was hypothesized to influence health risk behaviours in paths mediated by spirituality (religious well-being and existential well-being), and 2) in which spirituality (religious well-being and existential wellbeing) was hypothesized to influence health risk behaviours in paths mediated by intrinsic religiosity. Intrinsic religiosity failed to mediate the association between health risk behaviours and spirituality, and spirituality also failed to mediate the association between intrinsic religiosity and health risk behaviours. Nevertheless, there were direct relations between the religiosity/spirituality variables and most of the health risk behaviours measured in this study. Results showed that intrinsic religiosity and spirituality dimensions are independent constructs in this particular sample, since they failed to mediate each other. Our results support the putative bifurcation of the two constructs in the literature and findings of distinct independent roles they have on health.
\end{abstract}

Key words: Intrinsic Religiosity, Spirituality, Mediation, Health Risk Behaviours 
Examining religiosity and spirituality concepts and their protective role in health risk behaviour: Testing for mutual mediation.

\section{INTRODUCTION}

Interest in the association of religiosity and spirituality with health risk behaviours is increasing, and most of the studies project a protective role of the variables (Nonnemaker, McNeely, \& Blum, 2003; Yonker, Schnabelrauch, \& DeHaan, 2012). Both religiosity and spirituality are negatively associated with health risk behaviours such as engaging in early sex, having sex with multiple sexual partners (Gold et al., 2010; Miller \& Gur, 2002; Rostosky, Wilcox, Comer Wright, \& Randall, 2004; Zaleski \& Schiaffino, 2000), and using addictive licit and illicit substances, including alcohol and nicotine (Chitwood, Weiss, \& Leukefeld, 2008; Humphreys \& Gifford, 2006; Marsiglia, Kulis, Nieri, \& Parsai, 2005). Not only do religiosity and spirituality protect against risk, they also have some resilience properties (Reutter, \& Bigatti, 2014) and promote healthy behaviours such as the consumption of more fruits and vegetables and less unhealthy fats (Tan, Chan, \& Reidpath, 2013).

Nevertheless, some issues are outstanding, chief amongst which are: (1) difficulties in conceptualizing and distinguishing between religiosity and spirituality, and (2) the actual effect of the concepts on risk-taking behaviour. Religiosity and spirituality evolved from common origins. Classical descriptions of religiosity encompassed elements of what is now considered spirituality. However, over time, there tended to be an etymological/conceptual schism between the two concepts, each evolving into a distinct concept (Hill \& Pargament, 2003; Hill et al., 2000; Zinnbauer, Pargament, \& Scott, 1999). As things stand, religiosity tends to be associated with subscription to a set of institutionalized and most likely dogmatic beliefs and religious practices. Spirituality distinguishes itself from religiosity by its personalized, metaphysical focus. Although the 
concept has proven difficult to define (Moberg, 2002), spirituality is associated with an individualized, subjective experience, in some instance incorporating the idea of an existential relationship with God, a perceived transcendence or higher influence (Hill \& Pargament, 2003; Hill et al., 2000; Hodge, 2005).

Surveys of religiosity in industrialized societies reveal a trend towards more secularization and waning interest and commitment to religious institutions, and a concomitant declining influence of religion, at least in it's organized, formalized form (Hill et al., 2000). More and more people report less religiosity, being more spiritual than religious, and some even assert that they are neither religious nor spiritual (Zinnbauer \& Pargament, 2005). The emerging religiosity trends highlight the necessity of disentangling the concepts of religiosity and spirituality (Burke, Van Olphen, Eliason, Howell, \& Gonzalez, 2014). Research results will be more meaningful when measures of religiosity and spirituality are clearly differentiated, accepting the reality that the two constructs do share commonalities, yet they each encompass a distinct nomological net to preserve a differentiated conceptual identity. Divergence in their definitions is unavoidable.

Some researchers deal with the problem of divergence in the definitions of religiosity and spirituality by merging the two concepts (DeHaan, Yonker, \& Affholter, 2011; Foster, Young, Bryan, \& Quist, 2016; Holder, Durant, Harris, Daniel, Obeidallah, \& Goodman, 2000; Koenig, 2012). However, there is a trend of acknowledging the overlap between religiosity and spirituality, yet recognizing that they have distinct predictive roles to warrant separate assessment in health risk studies. The state of affairs is such that there is no clarity whether spir- 
Examining religiosity and spirituality concepts and their protective role in health risk behaviour: Testing for mutual mediation.

ituality and religiosity are overlapping concepts; or that spirituality is a component of religiosity, or that they are distinct concepts (cf. Benson, 2004, p. 49).

This study aims to clarify the commonalities between religiosity and spirituality, and their relationship to health risk behaviour, by using a mediational Structural Equation Modeling (SEM) approach. This type of analysis is pertinent in South Africa, a country where engagement in several types of risk behaviours have been successfully limited, yet the rates of occurrence remain rather high (Gray, Vawda, \& Jack, 2013; Shisana et al., 2013; World Health Organisation, 2011). Thus, establishing the relationship between spirituality and religiosity and their role in preventing engagement in risk behaviour is an important preventative effort.

\section{METHOD}

\section{Sample}

In total, the sample consisted of 333 Black African students who were conveniently drawn from the University of Limpopo, in South Africa. All respondents were single and $52.8 \%$ of them were female. Of this sample, $78.5 \%$ resided in the university's residences, $9.6 \%$ and $7.2 \%$ rented accommodation outside of campus, alone or with friends, respectively and $4.8 \%$ were day scholars and lived at home with their families of origin. The sample was recruited from three faculties of the institution, that is, Law and Management Sciences (31.9\%), Humanities (35.8\%) and, Science and Agriculture (32.2\%).

\section{Procedure}

Participants were recruited from undergraduate classes. The students were briefed about the aims of the study and invited to participate. They were also informed that participation in the study was voluntary. Those who consented to participate 
were also made aware of their rights as research participants, such as the right to withdraw from the study at any time, confidentiality and anonymity. Finally, prospective participants were required to complete an assent form before completing the study questionnaire. Once they did that, they were then provided with a questionnaire to be completed in their own time or in group settings where time was available during a lecture. One of the researchers was always available to answer further questions of clarification during data collection.

\section{Ethical consideration}

The study protocol was approved by the Research and Ethics Committee of the University of Limpopo.

\section{Measures}

\section{Demographic questionnaire}

The demographic details collected from participants included age, gender, domicile, university housing and the area of study at university.

\section{Spiritual Well-being Scale}

The Spiritual well-being (SWB) scale (Ellison, 1983; Paloutzian \& Ellison, 1982), a 20-item self-report measure, was used to measure spirituality. It was chosen for this study because its scores are positively correlated with an intrinsic orientation to religiosity (Boivin, Kirby, Underwood, \& Silva, 1999). The measure consists of two subscales of 10 items each, measuring components of religious well-being (RWB) and existential well-being (EWB), respectively. The RWB component is designed to tap into an individual's belief about his relationship with God. On the other hand, EWB evaluates a person's sense of purpose and meaning in life. An overall spiritual well-being (SWB) score is obtained by summing the 
Examining religiosity and spirituality concepts and their protective role in health risk behaviour: Testing for mutual mediation.

responses of all scale items. Items measuring the RWB subscale include: "I believe that God loves me and cares about me," and "My relationship with God contributes to my wellbeing". Items assessing the EWB are: "I don't know who I am, where I came from, or where I am going", and "I feel a sense of well-being about the direction my life is headed in." The measurement scale used to respond to each of the items had six steps ranging from "Strongly agree" (1) to "Strongly disagree" (6). The SWBS has high internal consistency and testretest reliability. The internal consistency reliability coefficients range from 0.82 to 0.94 for RWB, 0.78 to 0.86 for EWB, and 0.89 to 0.94 for SWB. Test-retest reliability over a 4 to 10 week period range from a low of 0.73 to a high of 0.99 for the EWB, RWB, SWB (Boivin et al., 1999). In this study the reliability coefficients obtained for the scale were $\alpha=0.801$ for RWB, $\alpha=0.757$ for EWB and $\alpha=0.865$ for the full-scale SWB.

Intrinsic Religiosity Revised Scale (Gorsuch \& McPherson, 1989)

The Intrinsic Religiosity scale $(I)$ of Gorsuch and McPherson's (1983) Age-Universal Intrinsic/Extrinsic Revised scale (I/E-R; Gorsuch \& McPherson, 1989) was administered to evaluate intrinsic religious orientation among students. Theoretical grounds precluded the utilization of the extrinsic religiosity subscale in this study. It taps participation in religious activities for personal gain. Extrinsic religiosity was excluded from analysis because of its instrumental focus. Items measuring intrinsic religiosity include: "It is important to me to spend time in private thought and prayer" and "My whole approach to life is based on my religion." They are measured on a five point scale ranging from 'Strongly disagree' (1) to 'Strongly agree' (5). The scale has previously been used successfully with a 
sample similar to the present one. In this study, reliability was estimated at a modest $\alpha=0.648$.

Risky health behaviours

The National College Health Risk Behaviors Scale (NCHRBS) (Centers for Disease Control and Prevention [CDC], 1997) was adapted for use in this study. The NCHRBS is a derivation and higher education version of the Youth Risk Behavior Surveillance System (YRBSS). In addition to its uses, it monitors priority health risks among American students in higher education institutions. Risky health behaviour aspects covered in this study included smoking, marijuana use, lack of balanced meals, sexual risk behaviour (infection with a sexually transmitted disease and experience with sexual intercourse) and consumption of alcoholic beverages. The self-administered questionnaire consists of 96 multiplechoice questions, rated on a 5-point Likert scale.

Data analysis

The SEM mediator analysis was conducted using AMOS 22.0 (Arbuckle, 2013). The first analyses considered spirituality as a mediator of the association between Intrinsic religiosity and health risk behaviour (alcohol intake, sexual behaviour, tobacco use, marijuana use, physical activity and diet) (see Figure 1a). Relatedly, the last set of analysis examined a hypothesized religiosity-mediated path model (Figure 1b), that proposed Intrinsic religiosity as a mediator of the relationship between Spirituality (RWB and EWB) and Health risk behaviour (Alcohol intake, sexual behaviour, tobacco use, marijuana use, physical activity and diet). 
Examining religiosity and spirituality concepts and their protective role in health risk behaviour: Testing for mutual mediation.

Figure 1a: Associations between spirituality/religiosity and health risk behaviours: Spirituality-mediated model

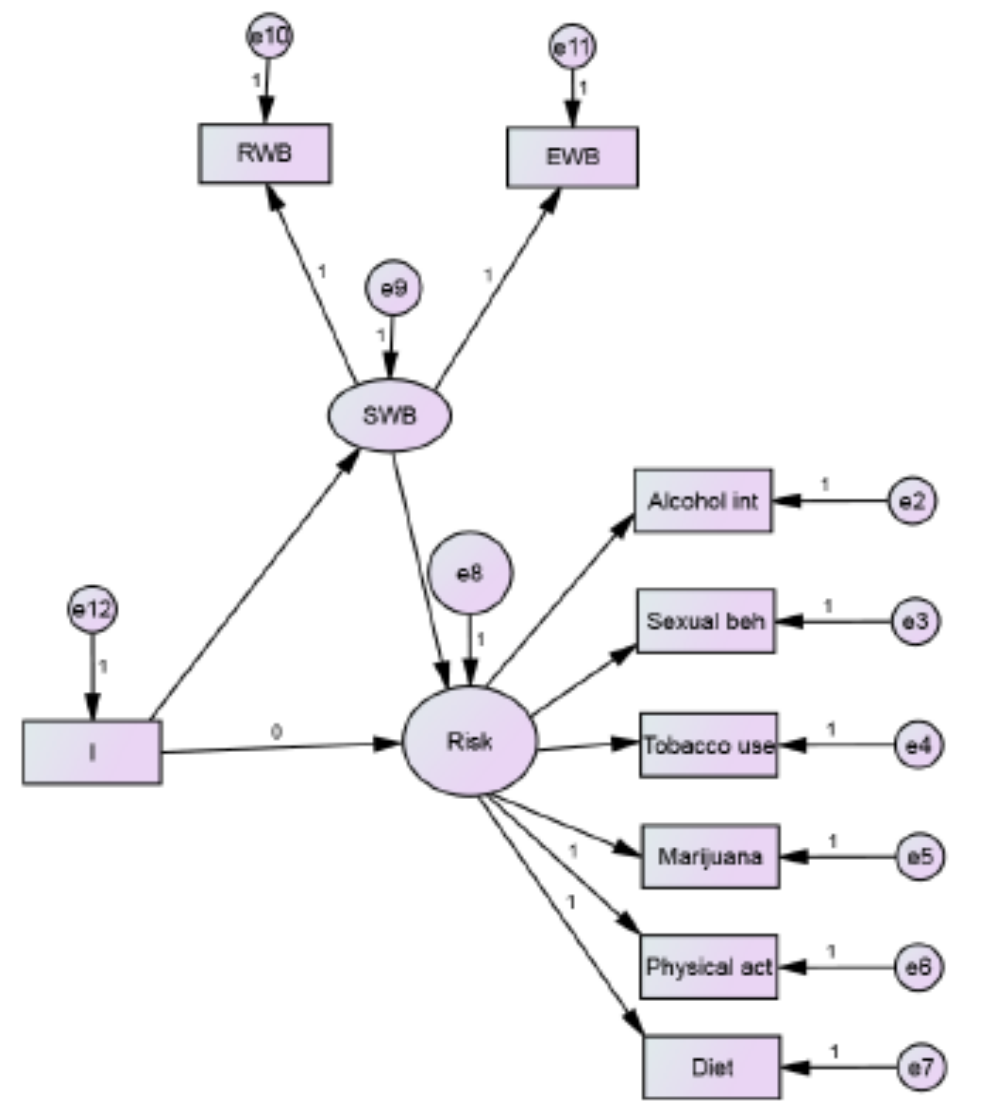

Note: I = Intrinsic religiosity; RWB = religious well-being; EWB = existential well-being. 
Figure 1b: Associations between spirituality/religiosity and health risk behaviours: Religiosity-mediated model

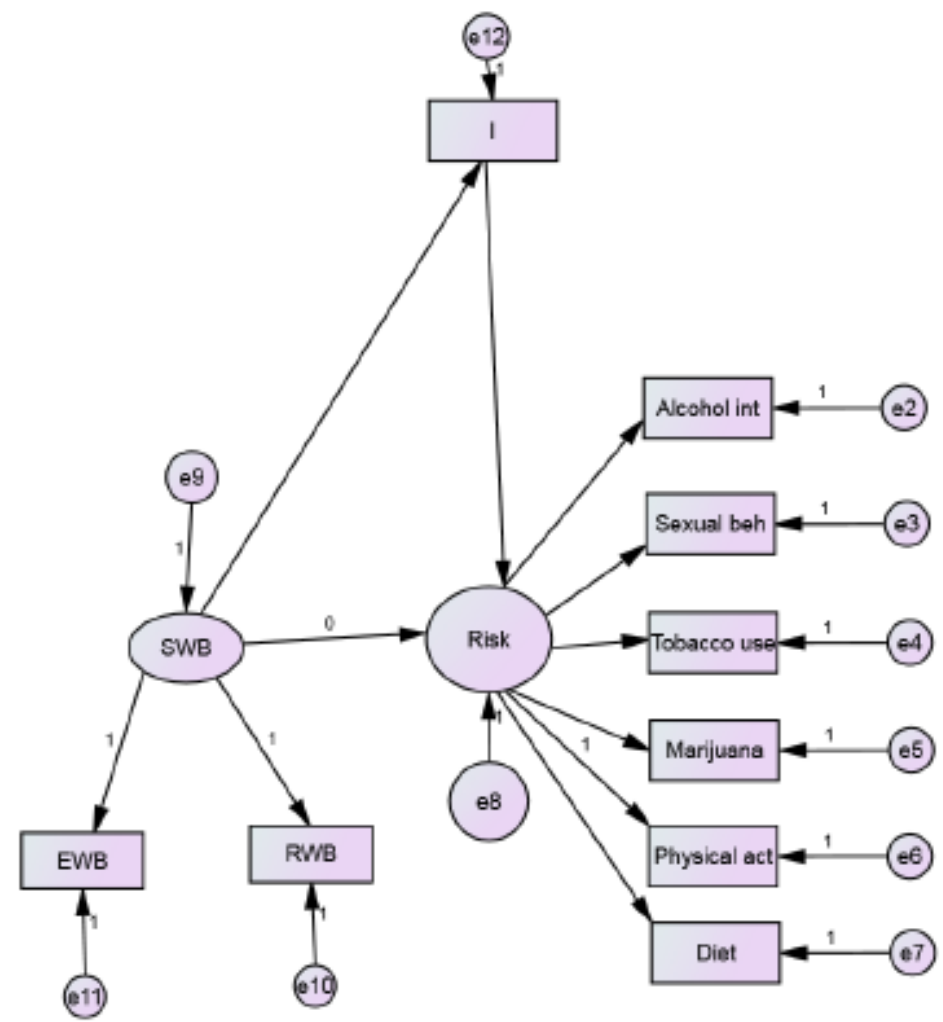

Note: I = Intrinsic religiosity; RWB = religious well-being; EWB = existential well-being.

Holmbeck's (1997) multi-step SEM strategy was followed to test the hypothesized models. The validity of the structural models was considered based on the statistical significance of the path coefficients, the chisquare difference test between the models and fit indices. The fit indices were reported based on the chisquare statistic $(p>0.05)$, the comparative fit index 
Examining religiosity and spirituality concepts and their protective role in health risk behaviour: Testing for mutual mediation.

(CFI; $\geq 0.95$ ), the goodness of fit index (GFI; > 0.90), the adjusted goodness of fit index (AGFI; $>0.80$ ), and the root mean square error of approximation (RMSEA; $<0.06$ ) along with its related $90 \%$ confidence interval.

\section{Results}

The correlations for spirituality, intrinsic religiosity and health risk behaviour are presented in Table 1. As the table demonstrates, most of the correlations are significant $(p<0.05)$. All the statistically significant correlations between I and health risk behaviours are negative. On the other hand, most statistically significant correlations between spirituality and health risk behaviours are positive. Nevertheless, there are important observations to be made about the correlations. The physical activity measure did not correlate with I and its association with religious wellbeing was modest at $r=$ $0.13, p<0.05$. The measure for diet was not related to either I or RWB $(p>0.05)$. Intake of alcohol was not associated with EWB $(p>0.05)$.

Table 1:

Correlations of intrinsic religiosity, spirituality, and health risk behaviour

\begin{tabular}{|c|c|c|c|c|c|c|c|c|}
\hline & 1 & 2 & 3 & 4 & 5 & 6 & 7 & 8 \\
\hline 1. Intrinsic religiosity & 1 & & & & & & & \\
\hline 2. Religious well-being & $-0.449^{\star \star}$ & & & & & & & \\
\hline 3. Existential well-being & $-0.244^{\star *}$ & $0.667^{* *}$ & 1 & & & & & \\
\hline 4. Sexual behaviour & $-0.248^{\star *}$ & $0.169^{* *}$ & 0.022 & 1 & & & & \\
\hline 5. Tobacco use & $-0.175^{\star \star}$ & $0.215^{\star \star}$ & $0.147^{*}$ & $0.408^{* *}$ & 1 & & & \\
\hline 6. Marijuana & $-0.179 * *$ & $0.206^{* *}$ & 0.093 & $0.328^{* *}$ & $0.552^{\star *}$ & 1 & & \\
\hline 7. Physical activity & -0.054 & $-0.135^{\star}$ & $-0.116^{*}$ & 0.033 & -0.063 & -0.080 & 1 & \\
\hline 8. Diet & -0.035 & 0.100 & 0.075 & 0.082 & $0.128^{\star}$ & 0.100 & -0.069 & 1 \\
\hline 9. Alcohol intake & $-0.249^{* *}$ & $0.165^{\star \star}$ & 0.095 & $0.413^{* *}$ & $0.403^{\star *}$ & $0.358^{\star *}$ & -0.100 & $0.117^{\star}$ \\
\hline
\end{tabular}

Note: ${ }^{* \star} p<0.01 ;{ }^{*} p<0.05$ 


\section{Spirituality-mediated model}

The hypothesized model proposed that the association between I and health risk behaviour would be mediated by spirituality. Model fit results in Table 2, show that all the three models demonstrated a good fit to the data. However, a second and essential criterion for evidence of mediation was not met, in that path coefficients in the predicted directions were not statistically significant in all the tested models (Direct effects model: $\beta=0.34, p=0.08$; Partial mediation: $\beta s=-0.32$ and 1.05, $p=0.05$ and 0.06; Full mediation: $\beta=-0.32$ and $1.05, p=0.05$ and 0.06 ). It would appear though, that based on the chi-square difference test (difference value $=3.48$ ) that the direct effects model had a better fit than both the partial and full (constrained) mediation models. These results suggest that spirituality does not mediate the association between $I$ and health risk behaviour.

Table 2: Fit indices for each mediation model test (spirituality as mediator)

\begin{tabular}{lcccccccc} 
Model & $X^{2}$ & $p$ & df. & CFI & GFI & AGFI & RMSEA & RMSEA Cl \\
\hline & & & & & & & & \\
Direct effects & 13.96 & 0.73 & 18 & 1.00 & 0.99 & 0.97 & 0.00 & $0.00,0.04$ \\
Partial mediation & 17.44 & 0.56 & 19 & 1.00 & 0.98 & 0.97 & 0.00 & $0.00,0.04$ \\
Full mediation & 17.44 & 0.56 & 19 & 1.00 & 0.98 & 0.97 & 0.00 & $0.00,0.04$ \\
\hline
\end{tabular}

\section{Religiosity-mediated model}

This model suggested that the relationship between spirituality and health risk behaviour would be mediated by intrinsic religiosity. Model fit results in Table 3, show that all of the three tested models demonstrated a good fit to the data. How- 
Examining religiosity and spirituality concepts and their protective role in health risk behaviour: Testing for mutual mediation.

ever, a second and essential criterion for evidence of mediation was not met, in that path coefficients in the predicted directions were not statistically significant in all the tested models (Direct effects model: $\beta=-0.15, p=0.96$; Partial mediation: $\beta s=-0.45$ and -0.31 , $p s<0.05$; Full mediation: $\beta=-0.45$ and -0.31 , ps $<0.05)$. This suggests that religiosity does not mediate the relationship between spirituality and health risk behaviour.

Table 3: Fit indices for each mediation model test (religiosity as mediator)

\begin{tabular}{lcccccccc}
\hline & & & & & & & & $90 \%$ \\
Model & $X^{2}$ & $p$ & df. & CFI & GFI & AGFI & RMSEA & RMSEA CI \\
\hline & & & & & & & & \\
Direct effects & 7.65 & 0.90 & 14 & 1.00 & 0.99 & 0.98 & 0.00 & $0.00,0.02$ \\
Partial mediation & 34.04 & 0.01 & 18 & 0.97 & 0.97 & 0.94 & 0.05 & $0.02,0.07$ \\
Full mediation & 34.47 & 0.01 & 18 & 0.97 & 0.97 & 0.94 & 0.05 & $0.02,0.07$ \\
\hline
\end{tabular}

\section{DISCUSSION}

This study sought to establish the conceptual relationship between intrinsic religiosity and spirituality by evaluating their capacity to mediate one another. In that respect, SEM was used to test two mediational models. In the first, I was hypothesized to influence health risk behaviours in a path mediated by spirituality (RWB and EWB). In the second, spirituality (RWB and EWB) was hypothesized to influence health risk behaviours in a path mediated by $I$. However, the hypotheses for religiosity and spirituality as mediators for each other were not supported by the results. Our findings are consistent with recent research that corroborates the differentiation of religiosity and spirituality (e.g., Burke et al., 2014; Reutter \& Bigatti, 
2014). This is in contrast to those who argue that the constructs are equivalent, in a sense that they have a large conceptual overlap or should mediate each other's effects (Koenig, 2009, 2012).

Nonetheless, this study confirmed the role of both spirituality and religiosity as significant protective resources, at least at the level of direct relations (Yonker et al., 2012). Consistent with the existing literature (Gold et al., 2010; Hayward, Owen, Koenig, Steffens, \& Payne, 2012; Tan et al., 2013) our findings demonstrate a strong association between religiosity, spirituality and most health outcomes.

The value of the study is in pursuing the type of research that seems to be missing in the studies of religiosity and spirituality (Reutter \& Bigatti, 2014). Specifically, this research contributes to the literature investigating the role of spirituality (e.g., Fabricatore \& Handal, 2000; Wallace \& Lahti, 2004) and religiosity as mediator variables. We assumed that since each of the variables share some characteristics; they may as well share properties such as mediation. Based on the findings of our study, intrinsic religiosity and spirituality do not mediate each other in their relationship with risk behaviour.

\section{Limitations}

We recognize that religiosity and spirituality have been operationalized in multiple ways by researchers. It is possible that any of the scales we have used in this study may not have been adequate measures of the variables. We have also conducted this research among students. Results with other populations, such as church-going adults, may produce different conclusions. 
Examining religiosity and spirituality concepts and their protective role in health risk behaviour: Testing for mutual mediation.

\section{References}

Arbuckle, J. L. (2013). IBM SPSS Amos 22 user's guide. Crawfordville, FL: Amos Development Corporation.

Benson, P. L. (2004). Commentary: Emerging themes in research on adolescent spiritual and religious development. Applied Developmental Science, 8, 47-50.

Boivin, M. J., Kirby, A. L., Underwood, L. K., \& Silva, H. (1999). Spiritual well-being scale. In P. C. Hill \& R. W. Hood, Jr. (Eds.), Measures of religiosity (pp. 382-385). Birmingham, AL: Religious Education.

Burke, A., Van Olphen, J., Eliason, M., Howell, R., \& Gonzalez, A. (2014). Re-examining religiosity as a protective factor: Comparing alcohol use by self-identified religious, spiritual, and secular college students. Journal of Religion \& Health, 53, 305-316. DOI:10.1007/s10943-012-9623-8

Centers for Disease Control and Prevention [CDC]. (1997). Youth risk behavior surveillance: National College Health Risk Behavior Survey - United States 1995. Surveillance Summaries, 46 (SS-6), 1-54.

Chitwood, D. D., Weiss, M. L., \& Leukefeld, C. G. (2008). A systematic review of recent literature on religiosity and substance use. Journal of Drug Issues 38(3), 653-688. DOI: $10.1177 / 002204260803800302$

DeHaan, L. G., Yonker, J. E., \& Affholter, C. (2011). More than enjoying the sunset: Conceptualization and measurement of religiosity for adolescents and emerging adults: Implications for developmental inquiry. Journal of Psychology \& Christianity, 30(3), 184-195.

Ellison, C. W. (1983). Spiritual well-being: Conceptualization and measurement. Journal of Psychology \& Theology, 11, 330-340.

Fabricatore, A. N., Handal, P. J., \& Fenzel, L. M. (2000). Personal spirituality as a moderator of the relationship between stressors and psychological well-being. Journal of Psychology \& Theology, 28(3), 221-228. 
Foster, D. W., Young, C. M., Bryan, J. L., \& Quist, M. C. (2016). Compounding risk: An examination of associations between spirituality/religiosity, drinking motives, and alcohol-related ambivalence among heavy drinking young adults. Addictive Behaviors, 63, 1-11.

Gold, M. A., Sheftel, A. V., Chiappetta, L., Young, A. J., Zuckoff, A., DiClemente, C. C., \& Primack, B. A. (2010). Associations between religiosity and sexual and contraceptive behaviors. Journal of Pediatric \& Adolescent Gynecology, 23, 290-297.

Gorsuch, R. L., \& McPherson, S. E. (1989). Intrinsic/extrinsic measurement: I/E-Revised and single-item scales. Journal for the Scientific Study of Religion, 28, 348-354.

Gray, A., Vawda, Y., \& Jack, C. (2013). Health policy and legislation. In: Padarath A, English R, (Eds.), South African Health Review 2012/13 (pp. 3-19). Durban, Health Systems Trust. Accessed from www.hst.org.za/publications/south-african-health-review-2012/13

Hayward, R. D., Owen, A. D., Koenig, H. G., Steffens, D. C., \& Payne, M. E. (2012). Religion and the presence and severity of depression in older adults. American Journal of Geriatric Psychiatry 20(2):188-92.

Hill, P. C., \& Pargament, K. I. (2003). Advances in the conceptualization and measurement of religion and spirituality: Implications for physical and mental health research. American Psychologist, 58, 64-74.

Hill, P. C., Pargament, K. I., Hood, R. W., McCullough, M. E., Swyers, J. P., Larson, D. B., \& Zinnbauer, B. J. (2000). Conceptualizing religion and spirituality: Points of commonality, points of departure. Journal for the Theory of Social Behavior, 30(1), 51-77.

Hodge, D. R. (2005). Developing a spiritual assessment toolbox: A discussion of the strengths and limitations of five different assessment methods. Journal of Health \& Social Work, 30(4), 314-324.

Holder, D. W., Durant, R. H., Harris, T. L., Daniel, J. H., Obeidallah, D., \& Goodman, E. (2000). The association 
Examining religiosity and spirituality concepts and their protective role in health risk behaviour: Testing for mutual mediation.

between adolescent spirituality and voluntary sexual activity. Journal of Adolescent Health, 26, 295-302.

Holmbeck, G. (1997). Towards terminological, conceptual, and statistical clarity in the study of mediators and moderators: Examples from the child clinical and pediatric psychology literature. Journal of Consulting \& Clinical Psychology, 65(4), 599-610.

Humphreys, K., \& Gifford, E. (2006). Religion, spirituality, and the troublesome use of substances. In W. Miller \& $\mathrm{K}$. M. Carroll (Eds.), Rethinking substance abuse: What the science says and what we should do about it (pp. 257 274). New York, NY: Guilford.

Koenig, H. G. (2012). Religion, spirituality, and health: The research and clinical implications. International Scholarly Research Network (ISRN Psychiatry), 2012, Article ID 278730, 33 pages. doi:10.5402/2012/278730

Koenig, H. G. (2009). Research on religion, spirituality, and mental health: A review. The Canadian Journal of Psychiatry, 54(5), 283-291.

Miller, L., \& Gur, M. (2002). Religiousness and sexual responsibility in adolescent girls. Journal of Adolescent Health, 31, 401-406.

Marsiglia, F. F., Kulis, S., Nieri, T., \& Parsai, M. (2005). God forbid! Substance use among religious and nonreligious youth. American Journal of Orthopsychiatry, 75, 585-598.

Moberg, D. O. (2002). Assessing and measuring spirituality: Confronting dilemmas of universal and particular evaluative criteria. Journal of Adult Development, 9(1), 47-60.

Nonnemaker, J. M., McNeely, C. A., \& Blum, R. W. (2003). Public and private domains of religiosity and adolescent health risk behaviors: Evidence from the National Longitudinal Study of Adolescent Health. Social Science \& Medicine, 57, 2049-2054.

Paloutzian, R. F., \& Ellison, C. W. (1982). Loneliness, spiritual well-being and the quality of life. In L. A. Peplau \& D. 
Perlman (Eds.), Loneliness: A sourcebook of current theory, research and therapy (pp. 224-237). New York: Wiley Interscience.

Reutter, K. K., \& Bigatti, S. M. (2014). Religiosity and spirituality as resiliency resources: Moderation, mediation, or moderated mediation? Journal for the Scientific Study of Religion, 53(1), 56-72.

Rostosky, S. S., Wilcox, B. L., Comer Wright, M. L., \& Randall, B. A. (2004). The impact of religiosity on adolescent sexual behavior: A review of the evidence. Journal of Adolescent Research, 19, 677-697. DOI:10.1177/074355840 3260019

Shisana, O., Labadarios, D., Rehle, T., Simbayi, L., Zuma, K., Dhansay, A., et al., \& the SANHANES-1 Team. (2013). South African National Health and Nutrition Examination Survey (SANHANES-1). Cape Town, South Africa: HSRC. Accessed from www.hsrc.ac.za/en/research-areas/Research Areas.../sanhanes-health-and-nutrition

Tan, M-M., Chan, C. K. Y., \& Reidpath, D. D. (2013). Religiosity and spirituality and the intake of fruit, vegetable, and fat: A systematic review. Evidence-Based Complementary \& Alternative Medicine, Article ID 146214, 18 pages. http://dx.doi.org/10.1155/2013/146214

Wallace, K., \& Lahti, E. (2004). Spirituality as a mediator of the relation between perceived stress and life satisfaction. Gerontologist, 44(1), 567-567.

World Health Organisation. (2011). Global status report on non-communicable diseases 2010. Geneva, Switzerland: WHO. Accessed from www.who.int/nmh/publications/ncd _report_full_en.pdf 